\section{Two-way multivariate analysis of variance: A BASIC program for microcomputers}

\author{
DANIEL COULOMBE \\ University of Ottawa, Ottawa, Ontario, Canada
}

Multivariate analysis of variance (MANOVA) is an expansion of the univariate ANOVA to cases involving more than one dependent variable. This technique allows one to perform a global analysis of the effects of a given number of independent variables on a set of dependent variables all correlated to varying degrees. When applicable, MANOVA should be preferred to subjecting the data to a series of univariate ANOVAs, since it provides safeguards against the increase in the margin of error inherent to multiple univariate tests. Furthermore, the procedure can reveal and take into account the relationships existing within the data set. Thus, it represents a more general and powerful method of data analysis than its univariate counterpart. The rational and computational procedures associated with this technique have been presented in Lindeman, Merenda, and Gold (1980) and Tatsuoka (1971). The purpose of the program presented here is to perform two-way MANOVA on independent samples comprising equal or unequal numbers of subjects. When the sample sizes are unequal, an unweighted-means analysis is performed. In all cases, the MANOVA is followed by multiple factorial discriminant analysis to identify the nature of the dimensions on which the groups might differ and to enable multiple comparisons between group centroids. In this case, the eigenstructure is obtained using the deflation-power method. The corresponding algorithm was derived from Douglass (1983).

Input. The program requests the number of levels of both factor A (row) and factor B (column), the number of variables $(V)$, and the number of subjects within each combination of factors (S). The raw data can then be entered either sequentially from the keyboard or from a disk file. In the latter case, the data file editor (described earlier, in Coulombe, 1983) can be used to generate a data file suitable as input to this program. The file contains, first, the total number of scores and then the scores themselves, from $A_{1} B_{1} S_{1} V_{1}$ to $A_{n a} B_{n b} S_{n(r c)} V_{n v}$, the last index moving fastest.

Output. All outputs are directed to the line printer. To obtain screen output, each LPRINT statement should be replaced by a PRINT statement. This can be achieved easily with the line editor (EDLIN) provided with MSDOS. Table 1 is a sample printout obtained using data presented in Lindeman et al., (1980, p. 233). After the

The author's mailing address is: School of Psychology, University of Ottawa, 275 Nicholas, Ottawa, Ontario, Canada K1N 6N5. scores observed in each cell are entered, the sums of squares and cross-products (SSCP) matrix for that cell is printed, followed by descriptive statistics for each variable. After data entry is completed, the SSCP matrices for error (Within), total, row, column, and interaction are printed, followed by the determinant values corresponding to each effect. Then, the MANOVA table, containing the computed values of Wilks' lambda, together with Bartlett's and Rao's tests of significance, is printed. Bartlett's statistic is approximately distributed as chisquare; Rao's statistic is approximately distributed as F. The appropriate number of degrees of freedom is printed in each case.

Table 1

Sample Output From MANOVA Programs

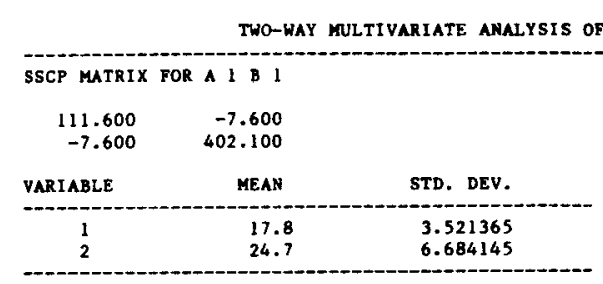

SSCP MATRIX POR A 1 B 2

\begin{tabular}{ccc}
109.600 & 130.199 \\
130.199 & 890.400 & \\
& & \\
VARIABLE & MEAN & STD. DEV. \\
\hline 1 & 30.2 & 3.489661 \\
2 & 56.4 & 9.946526 \\
\hline
\end{tabular}

\begin{tabular}{ccc} 
SSCP MATRIX FOR A 1 B 3 & \\
94.400 & 27.801 & \\
27.801 & 624.102 & \\
& & \\
VARIABLE & MEAN & STD. DEV. \\
\hline 1 & 46.4 & 3.238662 \\
2 & 66.3 & 8.327342
\end{tabular}

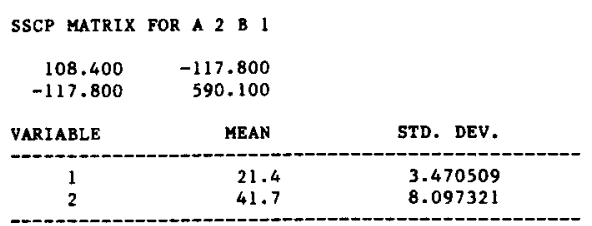

SSCP MATRIX FOR A 2 B 2

\begin{tabular}{crc}
$\begin{array}{c}109.600 \\
-3.801\end{array}$ & $\begin{array}{r}-3.801 \\
\end{array}$ & \\
VARIABLE & MEAN & STD. DEV. \\
\hline 1 & 37.800 & 3.489661 \\
\hline 2 & 55.6 & 8.733081 \\
\hline
\end{tabular}

SSCP MATRIX FOR A 2 B 3

$109.600 \quad-205.801$

$-205.801 \quad 1582.898$ 


\begin{tabular}{ccc} 
VARIABLE & MEAN & STD. DEV. \\
\hline 1 & 36.8 & 3.489661 \\
2 & 60.1 & 13.26189 \\
\hline
\end{tabular}

WITHIN SSCP MATRIX

$\begin{array}{rr}643.199 & -177.001 \\ -177.001 & 4776.001\end{array}$

TOTAL, SSCP MATRIX

$\begin{array}{rr}6451.734 & 7349.797 \\ 7349.797 & 16227.594\end{array}$

$\begin{array}{rr}\text { Sr MATRIX } \\ 4.272 & 26.680 \\ 26.680 & 166.680\end{array}$

Sc MATRIX

$4994.136 \quad 6953.604$

$6953.604 \quad 9811.221$

SrC MATRIX

$$
\begin{array}{lr}
810.132 & 546.523 \\
546.523 & 1473.711
\end{array}
$$

DETERMINANT TABLE

\begin{tabular}{ll}
\hline EFFECT & \multicolumn{1}{|c|}{ Sh + Sel } \\
\hline ROW & 3177649 \\
COLUMN & $3.631071 \mathrm{E}+07$ \\
ROW X COLIMN & $\mathbf{8 9 4 6 3 5 3}$ \\
ERROR & 3040590 \\
\hline
\end{tabular}

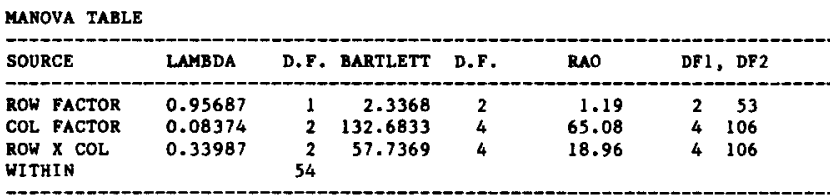

DISCRIMINANT FUNCTION ANALYSIS : ROW FACTOR

\begin{tabular}{|c|c|}
\hline Function & 1 \\
\hline $\begin{array}{l}\text { Eigenvalue } \\
\text { Discr. Pwr } \\
\text { Lambda } \\
\text { R-Squared } \\
\text { Chi-square } \\
\text { D. F. }\end{array}$ & $\begin{array}{c}0.04507 \\
1.00000 \\
0.95687 \\
0.04313 \\
2.3366 \\
2\end{array}$ \\
\hline Standardized & $\begin{array}{l}\text { Discriminant Function (weights): } \\
1\end{array}$ \\
\hline $\begin{array}{ll}x & 1 \\
x & 2\end{array}$ & $\begin{array}{l}0.8141 \\
0.5807\end{array}$ \\
\hline Discriminant & Function evaluated at Group Centroid \\
\hline$A$ & 1 \\
\hline $\begin{array}{l}54 . \\
56 .\end{array}$ & \\
\hline
\end{tabular}

DISCRIMINANT FUNCTION ANALYSIS : COLUMN FACTOR

\begin{tabular}{|c|c|c|}
\hline Function & 1 & 2 \\
\hline $\begin{array}{l}\text { Eigenvolue } \\
\text { Discr. Pur } \\
\text { Lambda } \\
\text { R-Squared }\end{array}$ & $\begin{array}{r}10.70971 \\
0.99398 \\
0.08374 \\
0.91626\end{array}$ & $\begin{array}{l}0.01984 \\
0.00184 \\
0.98055 \\
0.01945\end{array}$ \\
\hline
\end{tabular}

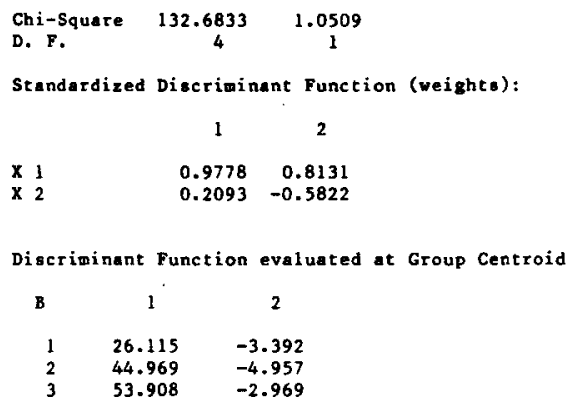

DISCRIMINANT FUNCTION ANALYSIS : INTERACTION FACTOR

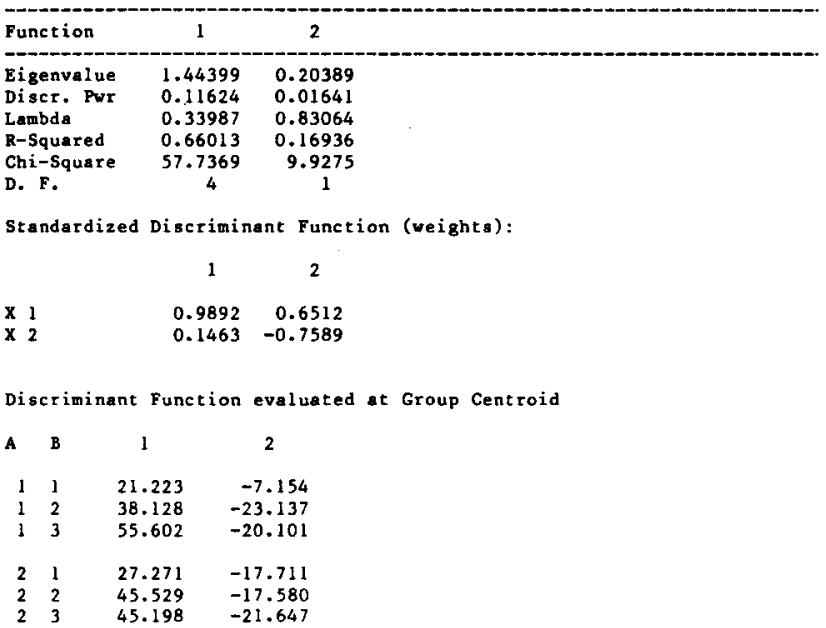

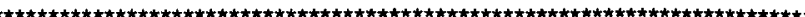

Following the MANOVA table, a discriminant function analysis is performed for each effect (row, column, and row $\times$ column interaction). The corresponding output includes, for each possible function: (1) the eigenvalues, (2) the index of discriminatory power, (3) Wilks' lambda, (4) the coefficient of determination, and (5) test of significance. Finally, the standardized discriminant function weights and the group centroids are printed.

Program Language and Requirements. The program was written in GW-BASIC on a Tandy 2000 with two disk drives, under MS-DOS. This language is directly compatible with that of the IBM PC and work-alikes. The program can be transported easily to other computers using Microsoft BASIC. It occupies about 9K of memory, leaving approximately $53 \mathrm{~K}$ for execution on the Tandy 2000 . Under these conditions, problems involving 10 levels of factor A, 10 levels of factor B, 15 variables, and 200 subjects per cell can be analyzed. Critical calculations are performed in double precision. Time requirements to execute the program can be decreased significantly by compiling it with a BASIC compiler.

Availability. A listing of the program is available free from the author. A diskette for the IBM PC or the Tandy 2000 is also available for $\$ 15.00$. Please send postal money order only. 


\section{REFERENCES}

Coulombe, D. (1983). MULREG: A multiple regression analysis system for microcomputers. Behavior Research Methods \& Instrumentation, $15,608$.

Douglass, B. P. (1983, August). Eigenvalues and eigenvectors. 80 Micro, pp. 328-339.
Lindeman, R. H., Merenda, P. F., \& Gold, R. Z. (1980). Introduction to bivariate and multivariate analysis. Glenview, IL: Scott, Foresman.

TATSUOKA, M. M. (1971). Multivariate analysis: Techniques for educational and psychological research. New York: Wiley.

(Revision accepted for publication February 12, 1985.) 